\title{
Erratum to: Serum Markers of Neurodegeneration in Maple Syrup Urine Disease
}

\author{
Giselli Scaini $^{1}$ - Tássia Tonon ${ }^{2,3}$ - Carolina F. Moura de Souza ${ }^{4}$ - Patricia F. Schuck ${ }^{5}$. \\ Gustavo C. Ferreira $^{6}$ • Joao Seda Neto ${ }^{7}$ • Tatiana Amorim ${ }^{8}$ • Ida Vanessa D. Schwartz ${ }^{4,9}$. \\ Emilio L. Streck ${ }^{1}$
}

Published online: 4 November 2016

(C) Springer Science+Business Media New York 2016

\section{Erratum to: Mol Neurobiol}

DOI 10.1007/s12035-016-0116-8

The original version of this article unfortunately contained mistakes.

The affiliation of the co-author "Tássia Tonon" should be changed to 2) BRAIN Laboratory (Basic Research and Advanced Investigations in Neurosciences), Hospital de Clínicas de Porto Alegre, Porto Alegre, Brazil AND 3) Post Graduation Program in Medicine: Medical Sciences, Universidade Federal do Rio Grande do Sul, Brazil.

The name of the co-author published as "Tatiana Amorin" should also be changed to the correct form which is Tatiana Amorim.

The online version of the original article can be found at http://dx.doi. org/10.1007/s12035-016-0116-8.

Emilio L. Streck

emiliostreck@gmail.com

1 Laboratório de Bioenergética e Núcleo de Excelência em NeurociênciasAplicadas de Santa Catarina (NENASC), Programa de Pós-Graduação em Ciências da Saúde, Universidade do Extremo Sul Catarinense, Av. Universitária, 1105, Criciúma, SC 88806-000, Brazil

2 BRAIN Laboratory (Basic Research and Advanced Investigations in Neurosciences), Hospital de Clínicas de Porto Alegre, Porto Alegre, Brazil

3 Post Graduation Program in Medicine: Medical Sciences, Universidade Federal do Rio Grande do Sul, Porto Alegre, Brazil
4 Medical Genetics Service, Hospital de Clínicas de Porto Alegre, Porto Alegre, RS, Brazil

5 Laboratório de Erros Inatos do Metabolismo, Programa de Pós-Graduação em Ciências da Saúde, Universidade do Extremo Sul Catarinense, Criciúma, SC, Brazil

6 Laboratório de Neuroquímica, Instituto de Biofísica Carlos Chagas, Universidade Federal do Rio de Janeiro, Rio de Janeiro, Brazil

7 Hospital Sirio Libanes, São Paulo, Brazil

8 Associação de Pais e Amigos dos Excepcionais (APAE), Salvador, Brazil

9 Department of Genetics, Universidade Federal do Rio Grande do Sul (UFRGS), Porto Alegre, Brazil 